\title{
Optimizing Reduced Graphene Oxide Aerogel for
}

\section{Supercapacitor}

Soon Poh Lee ${ }^{a}$, Gomaa A.M. Ali ${ }^{b}$, H.H. Hegazy ${ }^{c}$, Hong Ngee Lim ${ }^{d}$, Kwok Feng Chong ${ }^{a^{*}}$

${ }^{a}$ Faculty of Industrial Sciences \& Technology, Universiti Malaysia Pahang, Gambang, 26300

Kuantan, Malaysia

${ }^{\mathrm{b}}$ Chemistry Department, Faculty of Science, Al-Azhar University, Assiut 71524, Egypt

c Department of Physics, Faculty of Sciences, King Khalid University, P. O. Box 9004, Abha, Saudi Arabia

d Department of Chemistry, Faculty of Science, Universiti Putra Malaysia, 43400 UPM Serdang, Selangor, Malaysia

* Corresponding Author Fax: +609 5492766. E-mail: ckfeng@ump.edu.my 


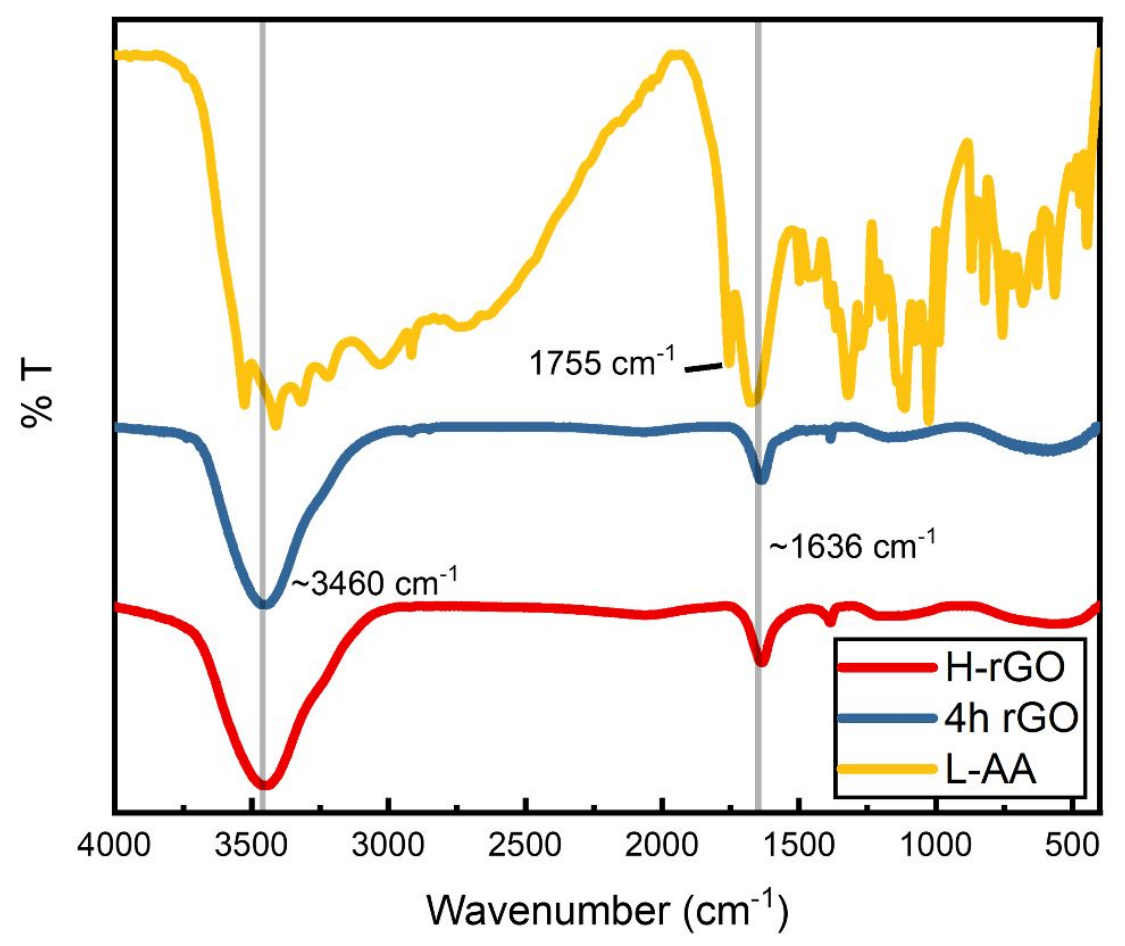

Figure S1 FTIR spectra of hydrazine reduced GO (H-rGO), 4h rGO and L-ascorbic acid (L-AA). 

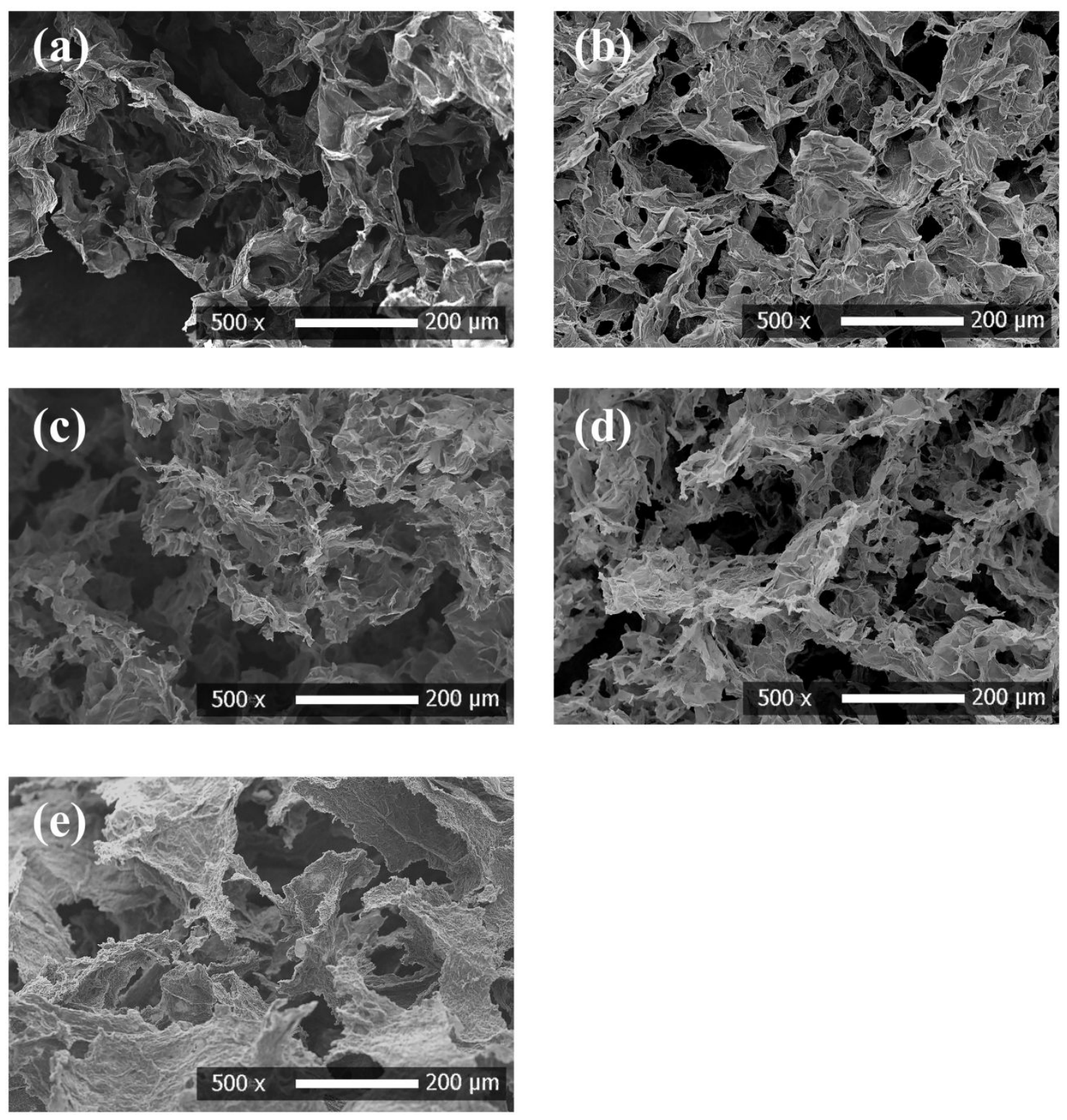

Figure S2 SEM images at 500× for (a) $0 \mathrm{~h} \mathrm{rGO,} \mathrm{(b)} 1 \mathrm{~h} \mathrm{rGO}$, (c) $4 \mathrm{~h} \mathrm{rGO}$, (d) $8 \mathrm{~h} \mathrm{rGO}$, and (e) $12 \mathrm{~h}$ rGO. 


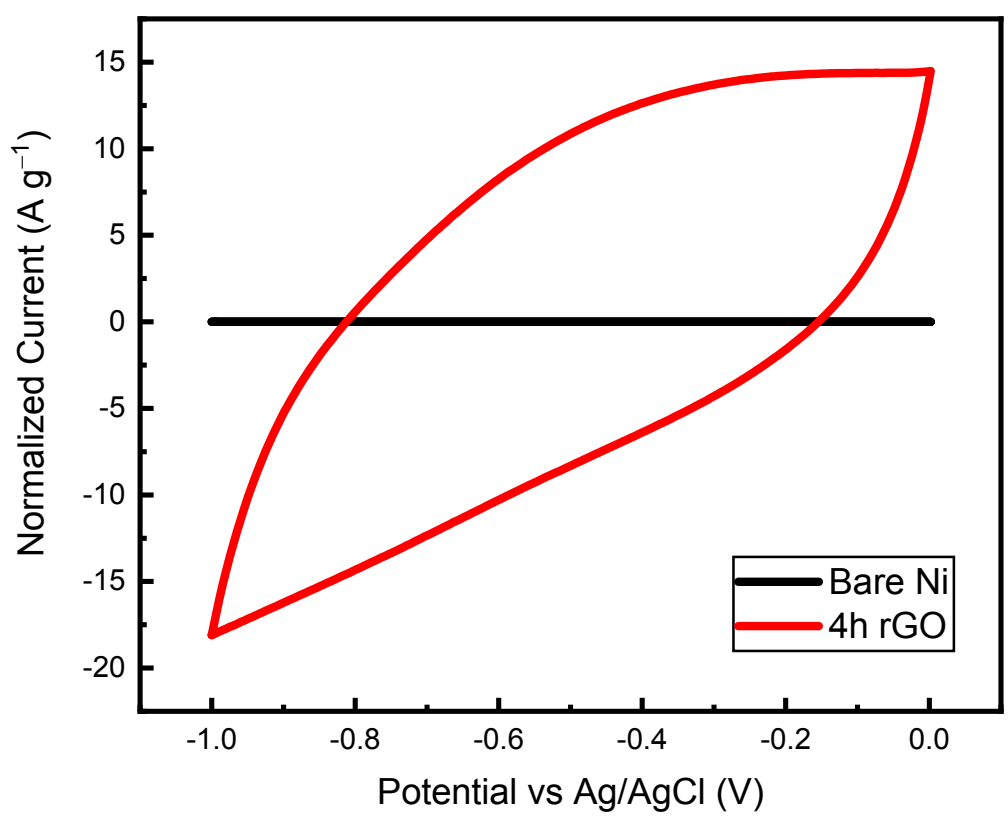

Figure S3 CV curves of bare nickel foam and $4 \mathrm{~h} \mathrm{rGO}$ at $75 \mathrm{mV} \mathrm{s}^{-1}$. 

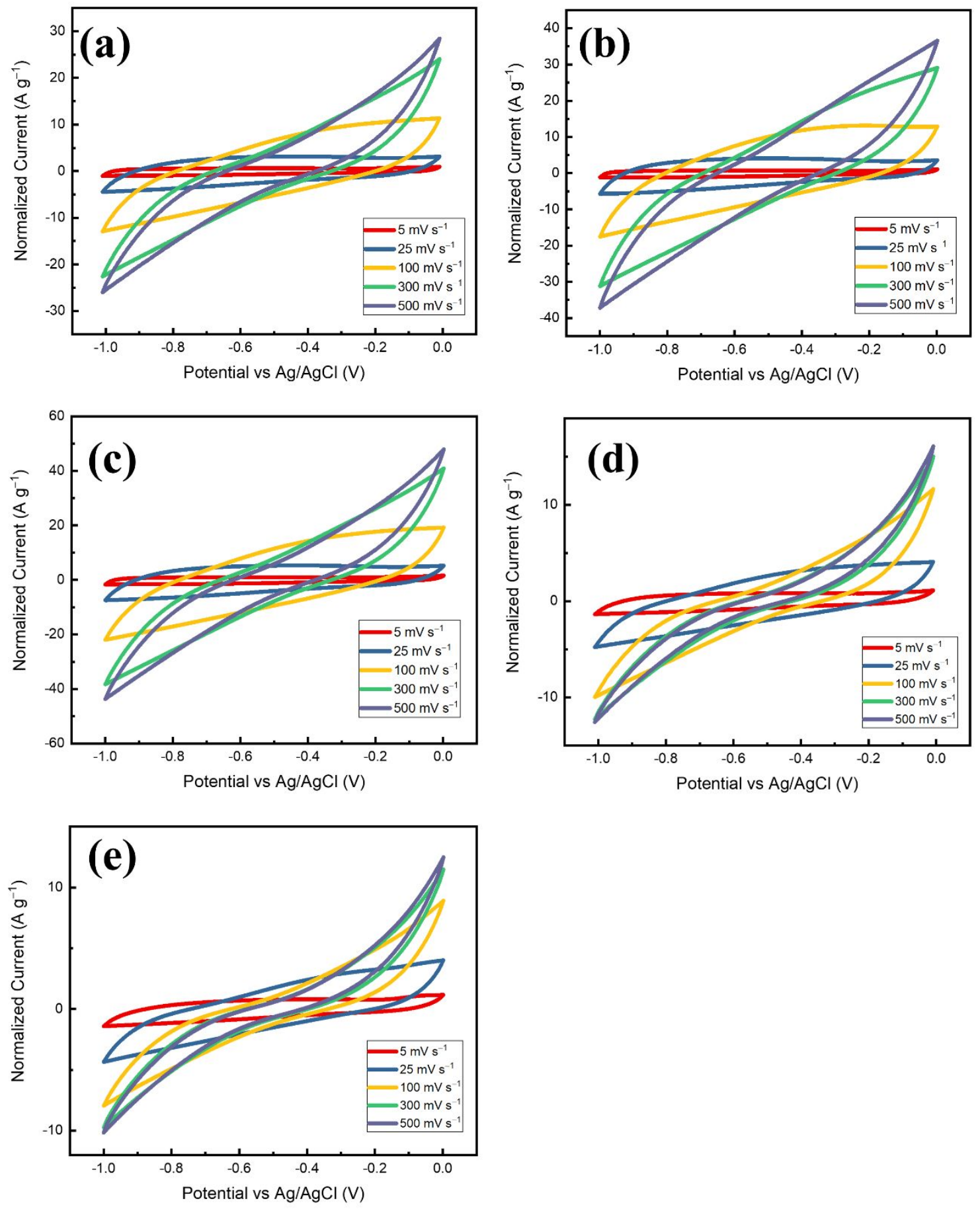

Figure S4 CV curves of different scan rate for (a) $0 \mathrm{~h} \mathrm{rGO,} \mathrm{(b)} 1 \mathrm{~h} \mathrm{rGO}$, (c) $4 \mathrm{~h} \mathrm{rGO,} \mathrm{(d)} 8 \mathrm{~h} \mathrm{rGO}$ and (e) $12 \mathrm{~h} \mathrm{rGO}$. 
Trasatti's analysis on the capacitive and diffusive contribution of the rGO samples are shown in Figure S2. It was calculated by using Equation (S1) as follows ${ }^{1,2}$ :

$$
Q_{T}=Q_{C}+Q_{D}
$$

Where $\mathrm{Q}_{\mathrm{T}}$ is the total charges stored, $\mathrm{Q}_{\mathrm{C}}$ is the capacitive charge storage behavior, and $\mathrm{Q}_{\mathrm{D}}$ is the diffusive charge storage behavior. The amount of charge for $\mathrm{Q}_{\mathrm{T}}$ and $\mathrm{Q}_{\mathrm{C}}$ can be derived and estimated from the plot of Equation (S2) and (S3) which is further shown in Figure S5 and summarized in Table S1.

$$
\begin{gathered}
Q_{V}=Q_{C}+\alpha v^{-1 / 2} \\
\frac{1}{Q_{V}}=\frac{1}{Q_{T}}+\alpha v^{1 / 2}
\end{gathered}
$$

where $\mathrm{Q}_{\mathrm{V}}$ represent the total measured voltammetric charge, $\alpha$ is a constant, and $v$ is the scan rate.
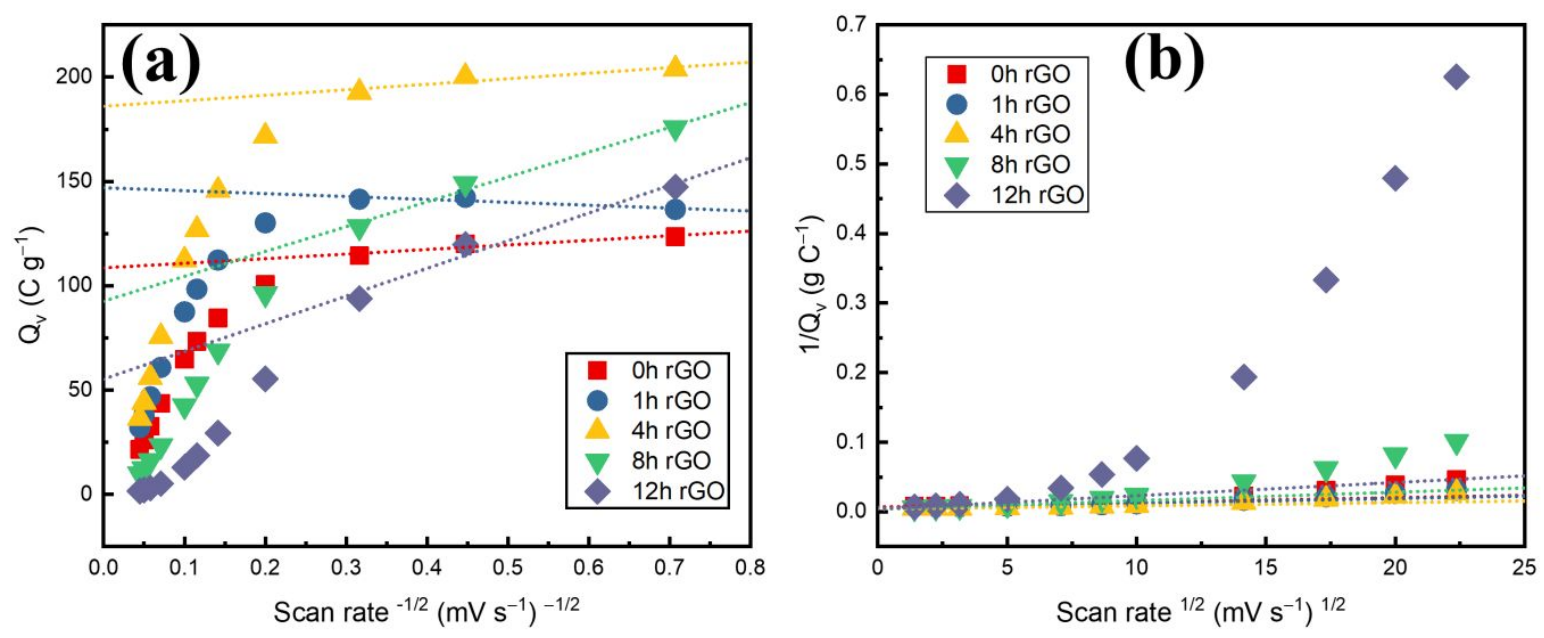

Figure S5 (a) The plot of normalized $Q_{v}$ and (b) the reciprocal normalized $Q_{v}$ versus $v^{-1 / 2}$. 
Table S1 Summary of capacitive and diffusive contribution with total capacitance for $0 \mathrm{~h}$ rGO, $1 \mathrm{~h}$ rGO, 4h rGO, $8 \mathrm{~h}$ rGO and $12 \mathrm{~h}$ rGO.

\begin{tabular}{|l|l|l|l|}
\hline Sample & $\mathbf{Q}_{\mathbf{c}}\left(\mathbf{C ~ g}^{-\mathbf{1}}\right)$ & $\mathbf{Q}_{\mathbf{D}}\left(\mathbf{C ~ g}^{-\mathbf{1}}\right)$ & $\mathbf{Q}_{\mathbf{T}}\left(\mathbf{C ~}^{\mathbf{- 1}}\right)$ \\
\hline rGO 0h & $108.6(74.5 \%)$ & $37.2(25.5 \%)$ & $145.8(100 \%)$ \\
\hline rGO 1h & $146.9(72.6 \%)$ & $55.2(27.4 \%)$ & $201.2(100 \%)$ \\
\hline rGO 4h & $186.0(72.2 \%)$ & $71.7(27.8 \%)$ & $257.7(100 \%)$ \\
\hline rGO 8h & $92.6(37.0 \%)$ & $157.4(63.0 \%)$ & $250.0(100 \%)$ \\
\hline rGO 12h & $55.3(22.7 \%)$ & $188.6(77.3 \%)$ & $243.9(100 \%)$ \\
\hline
\end{tabular}

Dunn's analysis on the capacitive and diffusive contribution area of the rGO samples are shown in Figure S3. The current density $(i)$ was calculated by using Equation (S4) for each fixed potential as follows ${ }^{3,4}$ :

$$
i=k_{1} v+k_{2} v^{\frac{1}{2}}
$$

Where $k_{1} v$ indicates the current density contributed from capacitive behavior and $k_{2} v^{\frac{1}{2}}$ indicates the current density contributed from diffusion behavior. The contribution can be calculated from the plot using Equation (S5) (by dividing $v^{\frac{1}{2}}$ on both side for Equation (S4)). Figure S6 shows one of the potentials $(-0.4 \mathrm{~V}$ vs $\mathrm{Ag} / \mathrm{AgCl})$ of $4 \mathrm{~h}$ rGO which took part in the calculation of Dunn's analysis.

$$
i v^{-\frac{1}{2}}=k_{1} v^{\frac{1}{2}}+k_{2}
$$




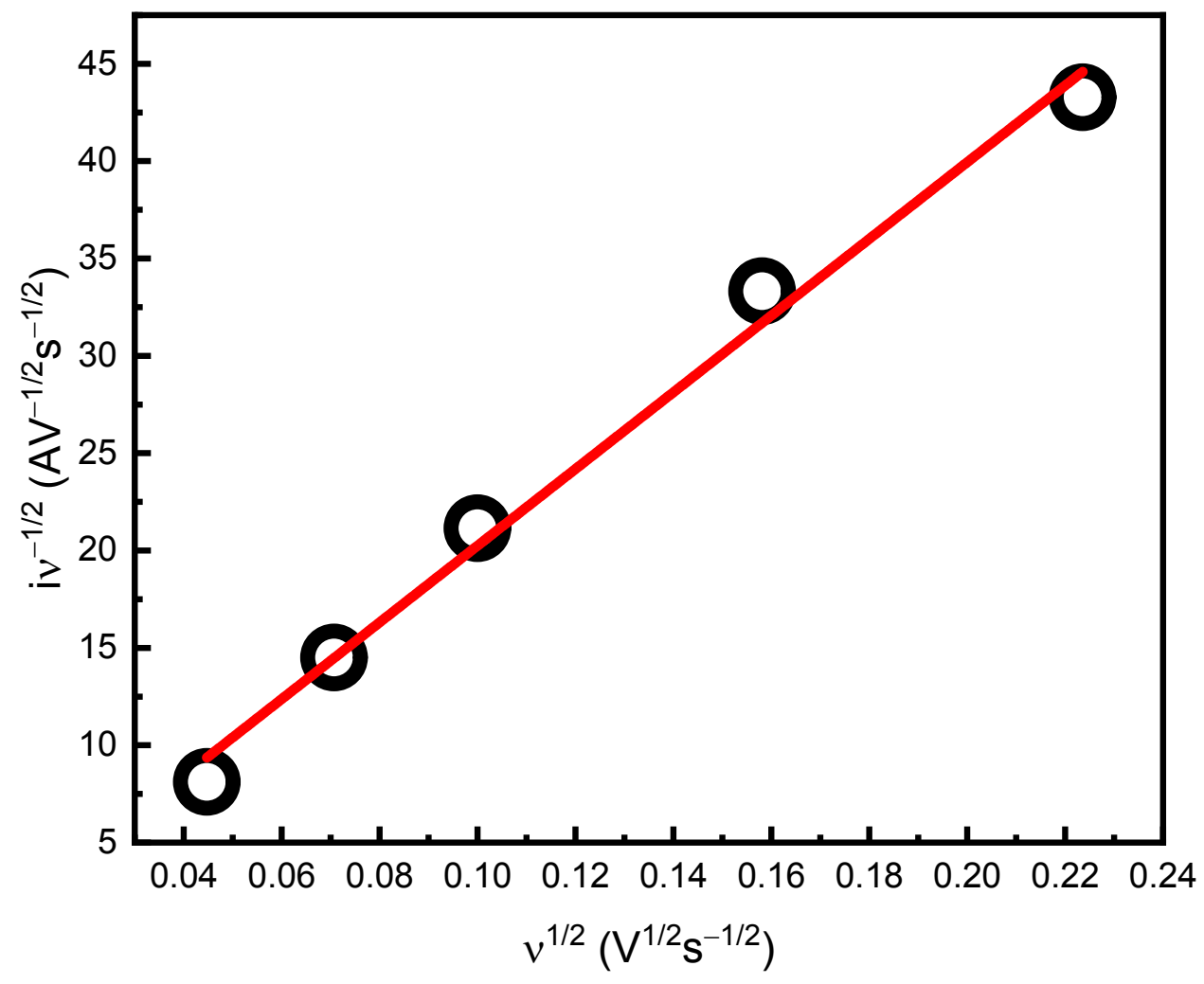

Figure S6 The anodic current plot of $i v^{-\frac{1}{2}}$ versus $v^{-\frac{1}{2}}$ at $-0.4 \mathrm{~V}$ vs $\mathrm{Ag} / \mathrm{AgCl}$ for $4 \mathrm{~h} \mathrm{rGO}$. 

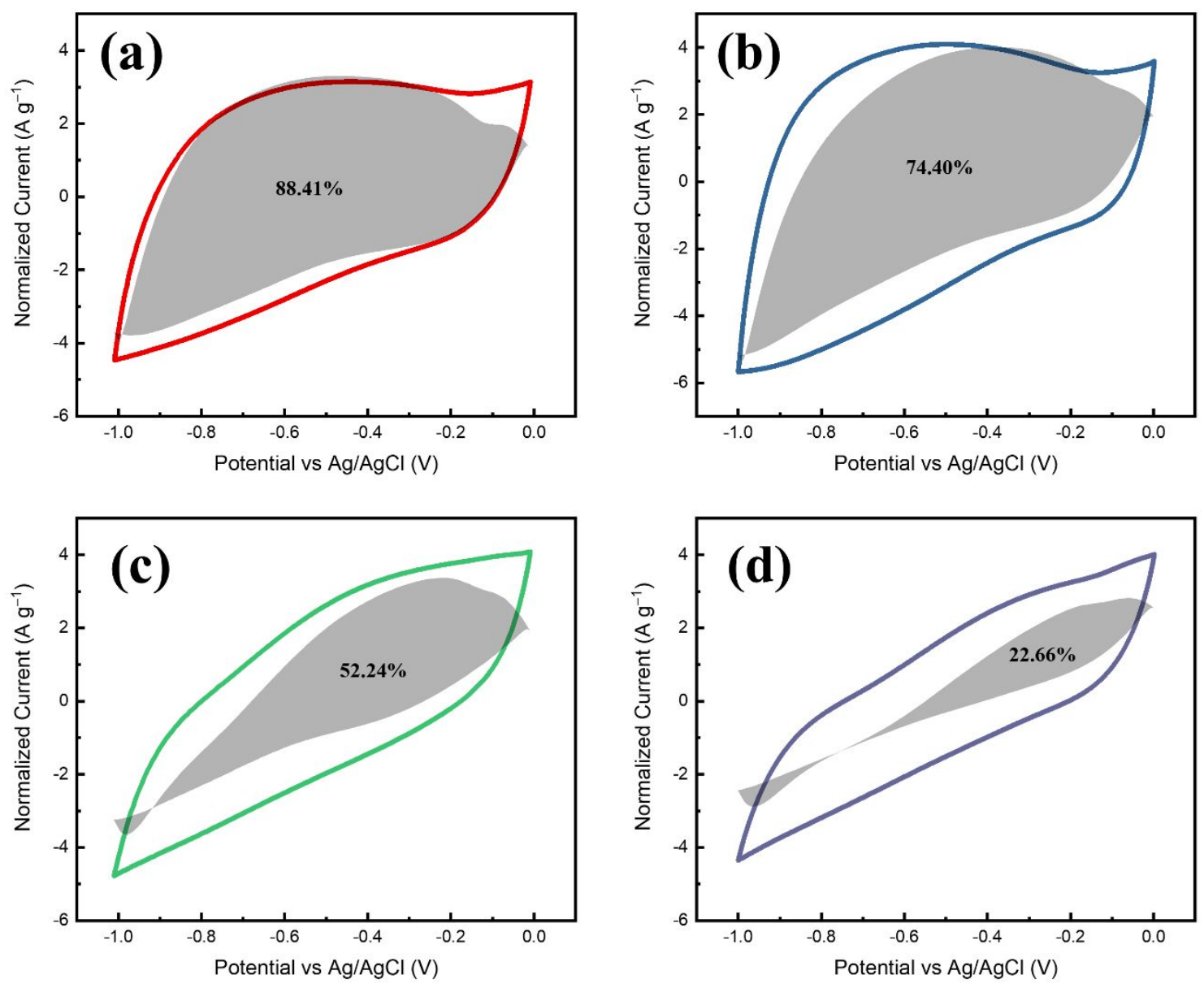

Figure S7 Dunn's analysis plot for capacitive contribution for (a) $0 \mathrm{~h} \mathrm{rGO,} \mathrm{(b)} 1 \mathrm{~h} \mathrm{rGO,} \mathrm{(c)} 8 \mathrm{~h} \mathrm{rGO}$ and (d) $12 \mathrm{~h} \mathrm{rGO}$. 

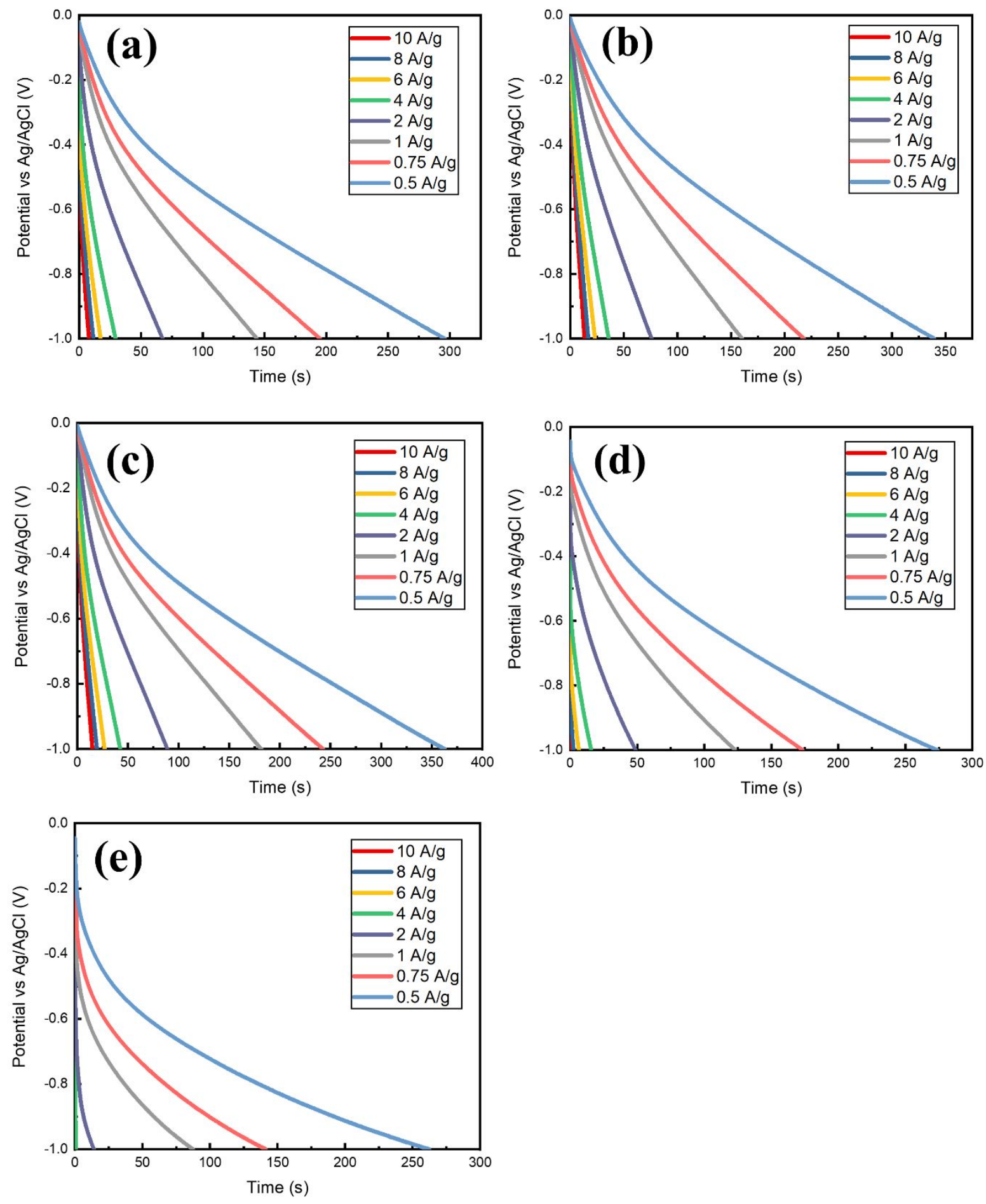

Figure S8 Galvanostatic discharge curves of different current densities for (a) $0 \mathrm{~h} \mathrm{rGO}$, (b) $1 \mathrm{~h} \mathrm{rGO}$, (c) $4 \mathrm{~h} \mathrm{rGO,} \mathrm{(d)} 8 \mathrm{~h} \mathrm{rGO}$ and (e) $12 \mathrm{~h} \mathrm{rGO.}$ 


\section{REFERENCES}

1. Thalji, M. R.; Ali, G. A. M.; Algarni, H.; Chong, K. F., $\mathrm{Al}^{3+}$ ion intercalation pseudocapacitance study of $\mathrm{W}_{18} \mathrm{O}_{49}$ nanostructure. Journal of Power Sources 2019, 438, 227028.

2. Kim, J. H.; Byeon, M.; Jeong, Y. C.; Lee, J.; Cho, H. I.; Shin, Y. E.; Yang, S. J.; Park, C. R., Revisit to the correlation of surface characteristic nature with performance of N-enriched carbon-based supercapacitor. Carbon 2018, 140, 68-76.

3. Zhou, Z.; Liu, T.; Khan, A. U.; Liu, G., Block copolymer-based porous carbon fibers. Science Advances 2019, 5 (2), eaau6852.

4. Wang, J.; Polleux, J.; Lim, J.; Dunn, B., Pseudocapacitive Contributions to Electrochemical Energy Storage in $\mathrm{TiO}_{2}$ (Anatase) Nanoparticles. The Journal of Physical Chemistry C 2007, 111 (40), 14925-14931. 